\title{
Ketepatan Parameter Klinis dalam Memprediksi Mortalitas Perdarahan Intrakranial Spontan pada Anak Usia Kurang dari Satu Tahun
}

\author{
Liveana Sugono,* Msy Rita Dewi, ${ }^{*}$ Erial Bahar** \\ *Bagian Kesehatan Anak, **Unit Penelitian Kesehatan Fakultas Kedokteran Universitas Sriwijaya/RS Moh. Hoesin, \\ Palembang
}

Latar belakang. Pada anak usia di bawah satu tahun, perdarahan intrakranial memiliki tingkat mortalitas yang tinggi. Diperlukan parameter untuk memprediksi mortalitas guna menentukan tata laksana segera yang tepat sehingga diperoleh hasil akhir yang lebih baik.

Tujuan. Mendapatkan tingkat akurasi parameter klinis dalam memprediksi mortalitas perdarahan intrakranial spontan pada anak dengan usia kurang dari satu tahun.

Metode. Dilakukan uji prognostik dengan data retrospektif dan prospektif dari rekam medik Januari 2009 -Desember 2014 terhadap anak usia di bawah satu tahun yang dirawat di rumah sakit Moh. Hoesin dengan perdarahan intrakranial tanpa riwayat trauma kepala. Parameter klinis yang diamati, yaitu gejala klinis dan neurologis, pemeriksaan laboratorium termasuk pT dan apTT. Dilakukan analisis untuk menentukan hubungan parameter dengan mortalitas.

Hasil. Didapatkan 136 anak yang memenuhi kriteria inklusi, 103 bertahan hidup, 33 meninggal dunia. Dari analisis multivariat ditemukan penurunan reflek cahaya, $\mathrm{GCS}<8, \mathrm{Hb}<7 \mathrm{~g} / \mathrm{dL}$ dan pemanjangan apTT memengaruhi mortalitas dengan probabilitas tertinggi $75,75 \%$. Kemudian disusun sistem skoring dengan alokasi skor berdasarkan Odds ratio. Didapatkan beberapa sistem skoring dengan sensitivitas antara 72,7\%-93,94\%, spesifisitas antara 42,72\%-77,67\% dan akurasi antara 55,15\%-76,47\%.

Kesimpulan. Berbagai parameter klinis ditemukan dapat memengaruhi mortalitas perdarahan intrakranial spontan pada anak usia di bawah satu tahun. Beberapa sistem skoring kemudian disusun dari temuan penelitian, meski belum memiliki nilai prediksi mortalitas yang ideal. Sari Pediatri 2015;17(4):255-60.

Kata kunci: perdarahan intrakranial spontan, mortalitas, parameter klinis

\section{Accuracy of Clinical Parameters for Predicting The Mortality of Spontaneous Intracranial Bleeding in Children Under One Year Old}

Liveana Sugono, ${ }^{*}$ Msy Rita Dewi, ${ }^{*}$ Erial Bahar**

Background.Spontaneous intracranial bleeding in children under one year old is associated with high mortality. Clinical parameters that canpredictmortality may benefit to determine appropriate prompt treatment and improve outcome.

Objective. To evaluate theaccuracy of various clinical parameters for predicting the mortality of spontaneous intracranial bleeding in children under one year old.

Methods. Prognostic study with combination of retrospective chartreview and prospective casesbetween January 2009 and December 2014 on children under one year old with intracranial bleeding withouthistory of head trauma treated in Pediatric Department of Moh Hoesin Hospital was performed. The clinical parameters evaluated consisted of clinical, neurological symptoms, and laboratory examinations including $\mathrm{p} T$ and apTT. Parameters were analyzed to identify their association with mortality.

Results. One hundred and thirty six children met the inclusion criteria, 103 survived and 33 died. Multivariate analysis identified decreased light reflex, GCS $<8, \mathrm{Hb}<7 \mathrm{~g} / \mathrm{dl}$, and prolonged apTT are associated with mortality with highest probability of $75.75 \%$. Various scoring systems were designed using odd ratio to allocate each parameterscores. The sensitivity for the scoring systems ranges between $72.7-93.94 \%$, specificity $42.72-77.67 \%$, and accuracy $55.15-76.47 \%$.

Conclusion.Various clinical parameters were found to be associated with mortality of spontaneous intracranial bleeding in children under one year old.Several scoring systems could be derived from the results of this study, however none yielded an ideal value for prediction of mortality. Sari Pediatri 2015;17(4):255-60.

Keywords: spontaneous intracranial bleeding, mortality, clinical parameters

\footnotetext{
Alamat korespondensi: Dr. Liveana Sugono. Bagian Kesehatan Anak FK Universitas Sriwijaya, Jl. Jenderal Sudirman KM 3,5 Palembang, Indonesia. Tel. +62-81374209631. E-mail: Liveanabeby@gmail.com
} 
$\mathrm{P}$ ada anak usia di bawah satu tahun, perdarahan intrakranial merupakan kondisi yang sering menyebabkan kematian atau kecacatan. Hasil penelitian sebelumnya di RS Moh. Hoesin (RSMH) Palembang menunjukkan 45\% angka kematian perdarahan intrakranial pada anak usia kurang dari satu tahun. ${ }^{1}$ Faktor yang diperkirakan dapat memengaruhi mortalitas antara lain adanya kelainan darah, lokasi perdarahan, volume perdarahan, usia, adanya kelainan neurologis penyerta, adanya komplikasi seperti edema serebri, hidrosefalus, serta kecepatan pemberian terapi. ${ }^{2-5}$

Pada penelitian yang telah dilakukan di RSMH ditemukan bahwa parameter yang diperoleh dari pemeriksaan klinis, antara lain jenis kelamin, usia, pucat, riwayat tidak diberikannya vitamin $\mathrm{K}$, riwayat diayun-ayun dan ubun-ubun membonjol dapat digunakan untuk memprediksi adanya perdarahan intrakranial. Parameter tersebut kemungkinan juga dapat digunakan untuk meramalkan mortalitas. ${ }^{1}$ Dengan meramalkan mortalitas pasien perdarahan intrakranial, terutama mortalitas secara tepat, tata laksana dini yang baik dapat dilakukan sehingga hasil akhir akan menjadi lebih baik. Penelitian ini dimaksudkan untuk mengetahui parameter klinis yang dapat memprediksi mortalitas perdarahan intrakranial pada anak usia kurang dari satu tahun di RSMH Palembang.

\section{Metode}

Penelitian uji prognostik untuk menilai akurasi parameter klinis dalam memprediksi mortalitas perdarahan intrakranial spontan pada anak usia kurang dari satu tahun di Departemen Kesehatan Anak RSMH Palembang. Sampel didapatkan secara retrospektif dari rekam medis RSMH antara Januari 2009 dan Desember 2013 ditambah data prospektif dari pasien yang dirawat antara Januari dan Desember 2014. Kriteria inklusi adalah anak usia kurang dari satu tahun dengan $C T$ scan kepala menunjukkan adanya perdarahan intrakranial tanpa riwayat trauma kepala. Data yang dikumpulkan berupa data demografi (usia, jenis kelamin), klinis, laboratorium dan jenis serta lokasi perdarahan intrakranial.

Variabel klinis yang dinilai berupa parameter klinis, meliputi umur, jenis kelamin, riwayat kejang, riwayat diayun, riwayat injeksi vitamin $\mathrm{K}$, riwayat muntah, penurunan kesadaran, pucat, ubun-ubun membonjol, penurunan reflek cahaya, pupil anisokordan gangguan motorik. Riwayat diayun-ayun adalah adanya riwayat mengayun bayi dengan intensitas dari akselerasi dan deselerasi kemudian dihentikan secara tiba-tiba. Pemeriksaan penunjang yang dilakukan berupa nilai $\mathrm{Hb}, \mathrm{pT}$, dan apTT. Ditentukan pemanjangan pT dan apTT (dua kali nilai kontrol, yaitu $\geq 26$ detik untuk pT dan $\geq 50$ detik untuk apTT).

Pengaruh parameter tersebut terhadap mortalitas perdarahan intrakranial dihitung menggunakan analisis multivariat regresi logistik. Kemudian dikembangkan sistem skoring klinis dengan memberikan bobot berbeda terhadap parameter prognostik sesuai hasil analisis. Dipilih titik potong dengan sensitivitas dan spesifisitas paling optimal untuk meramalkan mortalitas pada perdarahan intrakranial spontan. Analisis pada penelitian ini dilakukan dengan bantuan SPSS for Windows 16.00 (SPSS Inc).

\section{Hasil}

Terdapat 136 anak dengan perdarahan intrakranial yang memenuhi kriteria inklusi dan masuk dalam analisa, 103 bertahan hidup sedangkan 33 meninggal dunia. Subyek terdiri atas $89(65,4 \%)$ anak laki-laki dan 47 (34,6\%) perempuan dengan rerata usia 3,93 (SD 3,42) bulan. Pemeriksaan CT scan kepala menunjukkan 70 $(51,5 \%)$ anak dengan perdarahan subdural, $48(48 \%)$ intraserebral, $8(5,9 \%)$ subarachnoid, $48(35,3 \%)$ intraventrikular, dan $2(1,5 \%)$ epidural. Penurunan kesadaran terjadi pada 120 anak $(88,2 \%)$, dengan 59 $(43,4 \%)$ memiliki GCS kurang dari 8, riwayat kejang ditemukan $126(92,6 \%)$, riwayat tidak diberi vitamin K 85 (62,5\%), riwayat diayun-ayun 64 (47,1\%) anak. Pada pemeriksaan ditemukan terdapat demam pada 39 (26,5\%), pucat $96(70,6 \%)$, muntah $57(41,9 \%)$, ubun-ubun besar membonjol 119 (87,5\%), reflek cahaya menurun $55(40,4 \%)$ dan pupil anisokor 64 $(47,1 \%)$ anak. Pada hasil pemeriksaan laboratorium nilai apTT memanjang ditemukan pada $74(54,4 \%)$, pT memanjang 69 (50,7\%), anemia 81 (59,6\%), dan trombositopenia 16(11,8\%) anak. Perdarahan dengan melibatkan satu lobus hanya didapatkan pada 30 anak $(22,1 \%)$. Sebaran parameter pada anak dengan mortalitas hidup dan meninggal tertera pada Tabel 1 .

Ditemukan beberapa parameter dengan proporsi kejadian yang lebih tinggi pada anak yang meninggal, yaitu muntah, pucat, riwayat diayun, penurunan reflek 
Tabel 1. Karakteristik parameter klinis terhadap mortalitas $(\mathrm{n}=136)$

\begin{tabular}{|c|c|c|c|c|c|c|}
\hline \multirow{3}{*}{ Karakteristik } & & \multicolumn{4}{|c|}{ Meninggal } & \multirow{3}{*}{$\mathrm{p}$} \\
\hline & & \multicolumn{2}{|c|}{ Ya } & \multicolumn{2}{|c|}{ Tidak } & \\
\hline & & $\mathrm{n}$ & $\%$ & $\mathrm{n}$ & $\%$ & \\
\hline \multirow{2}{*}{ Jenis kelamin } & Laki-laki & 22 & 66,7 & 67 & 65 & $0,868^{*}$ \\
\hline & Perempuan & 11 & 33,3 & 36 & 35 & \\
\hline \multirow{2}{*}{ Klasifikasi umur (bulan) } & $1-3$ & 29 & 87,9 & 97 & 94,2 & $0,228^{*}$ \\
\hline & $>3-12$ & 4 & 12,1 & 6 & 5,8 & \\
\hline \multirow[t]{2}{*}{ Penurunan kesadaran } & Ada & 32 & 97 & 88 & 85,4 & $0,074^{*}$ \\
\hline & Tidak ada & 1 & 3 & 15 & 14,6 & \\
\hline \multirow[t]{2}{*}{ Kejang } & Ada & 30 & 90,9 & 96 & 93,2 & $0,660^{*}$ \\
\hline & Tidak & 3 & 9,1 & 7 & 6,8 & \\
\hline \multirow[t]{2}{*}{ Demam } & Ada & 7 & 21,2 & 32 & 31,1 & $0,276^{*}$ \\
\hline & Tidak & 26 & 78,8 & 71 & 68,9 & \\
\hline \multirow[t]{2}{*}{ Muntah } & Ada & 20 & 60,6 & 37 & 35,9 & $0,012^{*}$ \\
\hline & Tidak & 13 & 39,4 & 66 & 64,1 & \\
\hline \multirow[t]{2}{*}{ Pucat } & Ada & 29 & 87,9 & 67 & 65 & $0,012^{*}$ \\
\hline & Tidak & 4 & 12,1 & 36 & 35 & \\
\hline \multirow[t]{2}{*}{ Injeksi vitamin $\mathrm{K}$} & Tidak & 11 & 33,3 & 40 & 38,8 & $0,570^{*}$ \\
\hline & Ada & 22 & 66,7 & 63 & 61,2 & \\
\hline \multirow[t]{2}{*}{ Riwayat diayun-ayun } & Ada & 21 & 63,6 & 43 & 41,7 & $0,028^{*}$ \\
\hline & Tidak & 12 & 36,4 & 60 & 58,3 & \\
\hline \multirow[t]{2}{*}{ Ubun-ubun besar } & Membonjol & 29 & 87,9 & 90 & 87,4 & $0,940^{*}$ \\
\hline & Tidak membonjol & 4 & 12,1 & 13 & 12,6 & \\
\hline \multirow[t]{2}{*}{ Refleks cahaya } & Menurun & 23 & 69,7 & 32 & 31,1 & $<0,001^{*}$ \\
\hline & Normal & 10 & 30,3 & 71 & 68,9 & \\
\hline \multirow[t]{2}{*}{ Pupil } & Anisokor & 24 & 72,7 & 40 & 38,8 & $0,001^{*}$ \\
\hline & Isokor & 9 & 27,3 & 63 & 61,2 & \\
\hline \multirow[t]{2}{*}{ Trombosit (/dL) } & $<150.000$ & 3 & 9,1 & 13 & 12,6 & $0,584^{*}$ \\
\hline & $\geq 150.000$ & 30 & 90,9 & 90 & 87,4 & \\
\hline \multirow[t]{2}{*}{ ApTT (mg\%) } & Memanjang & 24 & 72,7 & 50 & 48,5 & $0,015^{*}$ \\
\hline & Tidak memanjang & 9 & 27,3 & 53 & 51,5 & \\
\hline \multirow[t]{2}{*}{$\mathrm{pT}(\mathrm{mg} \%)$} & Memanjang & 20 & 60,6 & 49 & 47,6 & $0,192^{*}$ \\
\hline & Tidak memanjang & 13 & 39,4 & 54 & 52,4 & \\
\hline \multirow[t]{2}{*}{ GCS } & $<8$ & 22 & 66,7 & 37 & 35,9 & $0,002^{*}$ \\
\hline & $\geq 8$ & 11 & 33,3 & 66 & 64,1 & \\
\hline \multirow[t]{2}{*}{ Hemoglobin $(\mathrm{mg} / \mathrm{dL})$} & $<7$ & 26 & 78,8 & 55 & 53,4 & $0,010^{*}$ \\
\hline & $\geq 7$ & 7 & 21,2 & 48 & 46,6 & \\
\hline \multirow[t]{5}{*}{ Jenis perdarahan ${ }^{* * *}$} & SAH & 4 & 12,1 & 4 & 3,9 & $0,058^{* *}$ \\
\hline & SDH & 11 & 33,3 & 59 & 57,3 & \\
\hline & $\mathrm{EDH}$ & 1 & 3 & 1 & 1 & \\
\hline & $\mathrm{ICH}$ & 16 & 48,5 & 32 & 31,1 & \\
\hline & IVH & 1 & 3 & 7 & 6,8 & \\
\hline \multirow[t]{2}{*}{ Lokasi perdarahan } & $>1$ lobus & 26 & 78,8 & 80 & 77,7 & $0,893^{*}$ \\
\hline & Satu lobus & 7 & 21,2 & 23 & 22,3 & \\
\hline
\end{tabular}

* Uji kai kuadrat; ** Uji Kolmogorov smirnov; ${ }^{* * *} \mathrm{SAH}=$ Subarachnoid hemorrhage, EDH= Epidural hemorrhage, IVH= Intraventrcular hemorrhage, $\mathrm{SDH}=$ Subdural hemorrhage, $\mathrm{ICH}=$ Intra cerebral hemorrhage 
cahaya, GCS $<8$, pupil anisokor, $\mathrm{Hb}<7 \mathrm{mg} / \mathrm{dL}$, dan pemanjangan aPTT. Untuk identifikasi parameter klinis yang paling berpengaruh dilakukan analisis multivariat dengan menggunakan regresi logistik. Hasil analisis tertera pada Tabel 2.

Dari analisis regresi logistik ditemukan empat persamaan ini akan didapatkan nilai p dari y maksimal 75,75\% (nilai probabilitas tertinggi).

Berdasarkan parameter faktor risiko (Tabel 2), dicoba disusun sistem skoring klinis praktis untuk memprediksi mortalitas. Terdapatbeberapa metode dalam menentukan bobot parameter faktor risiko,

Tabel 2. Analisis multivariat parameter klinis terhadap mortalitas pasien perdarahan intrakranial spontan

\begin{tabular}{lcccc}
\hline Variabel & koefisien & $\mathrm{p}$ & OR adj. & IK \\
\hline Reflek cahaya & 1,518 & 0,01 & 4,562 & $1,804-11,538$ \\
Klasifikasi GCS & 1,391 & 0,004 & 4,020 & $1,558-10,369$ \\
Klasifikasi Hb & 1,411 & 0,008 & 4,090 & $1,441-11,663$ \\
Klasifikasi apTT & 1,083 & 0,320 & 2,951 & $1,101-7,931$ \\
Konstanta & $-4,264$ & & & \\
\hline
\end{tabular}

Regresi logistik, nilai $\mathrm{p}=0,05$; OR adj. = odd ratio adjusted; $\mathrm{IK}=$ interval kepercayaan

parameter klinis yang memiliki hubungan bermakna terhadap mortalitas, yaitu penurunan reflek cahaya, $\mathrm{GCS}<8, \mathrm{Hb}<7 \mathrm{~g} / \mathrm{dL}$ dan pemanjangan apTT. Didapatkan persamaan sebagai berikut,

Klasifikasi reflek cahaya bernilai 1 jika menurun dan 0 jika normal, klasifikasi $\mathrm{Hb}$ bernilai 1 jika $\mathrm{Hb}<7$, dan 0 jika $\mathrm{Hb} \geq 7$, klasifikasi GCS bernilai 1 jika GCS $<8$ dan 0 jika GCS $\geq 8$, klasifikasi apTT bernilai 1 jika apTT $\geq 50$ detik dan 0 jika apTT $<50$ detik. Dari hasil sehingga disusun beberapa sistem skoring berbeda, yang kemudian akan diukur nilai diagnostiknya. Cara penyusunan sistem skoring pertama menggunakan skor 1 untuk faktor risiko dan skor 0 untuk yang bukan faktor risiko.Cara berikutnya yaitu dengan memberikan skor berdasarkan nilai Odd ratio adjusted dari analisis multivariat, jika OR $\geq 4$ diberi skor 2 dan jika OR $<4$ diberi skor 1 . Bentuk-bentuk variasi lain sistem skoring ini memberikan skor antara 1-4 pada

$y=-4,264+(1,518 x$ reflek cahaya $)+(1,391$ x klasifikasi GCS $)+(1,411$ x klasifikasi Hb $)+(1,083$ x klasifikasi apTT $)$

Tabel 3. Modifikasi sistem skoring berdasarkan parameter klinis

\begin{tabular}{|c|c|c|c|c|c|c|}
\hline Sistem skoring & Parameter klinis & 0 & 1 & 2 & 3 & 4 \\
\hline \multirow[t]{4}{*}{ A } & Reflek cahaya & Normal & Menurun & & & \\
\hline & GCS & $\geq 8$ & $<8$ & & & \\
\hline & $\mathrm{Hb}$ & $\geq 7$ & $<7$ & & & \\
\hline & apTT & Normal & Memanjang & & & \\
\hline \multirow[t]{4}{*}{ B } & Reflek cahaya & & Normal & Menurun & & \\
\hline & GCS & & $\geq 8$ & $<8$ & & \\
\hline & $\mathrm{Hb}$ & & $\geq 7$ & $<7$ & & \\
\hline & apTT & & Normal & Memanjang & & \\
\hline \multirow[t]{4}{*}{$\mathrm{C}$} & Reflek cahaya & & Normal & & Menurun & \\
\hline & GCS & & $\geq 8$ & & $<8$ & \\
\hline & $\mathrm{Hb}$ & & $\geq 7$ & & $<7$ & \\
\hline & apTT & & Normal & & Memanjang & \\
\hline \multirow[t]{4}{*}{$\mathrm{D}$} & Reflek cahaya & & & Normal & & Menurun \\
\hline & GCS & & & $\geq 8$ & & $<8$ \\
\hline & $\mathrm{Hb}$ & & & $\geq 7$ & & $<7$ \\
\hline & apTT & & & Normal & & Memanjang \\
\hline
\end{tabular}


parameter yang diukur sesuai Odd ratio adjusted. Empat di antara sistem skoring yang diuji disebut sistem skoring $\mathrm{A}, \mathrm{B}, \mathrm{C}$, dan $\mathrm{D}$ dengan rincian pemberian skor tertera pada Tabel 3.

Validitas masing-masing sistem skoring dalam memprediksi mortalitas diuji menggunakan receiver operator curve (ROC). Dari analisis tersebut diidentifikasi titik potong optimal skor parameter klinis dalam memprediksi mortalitas perdarahan intrakranial spontan. Uji validitas terhadap sistem skoring yang disusunsecara empiris tersebutdilakukan dengan berbagai percobaan terhadap seluruh parameter klinis hasil analisis multivariat dengan sistem skoring dan berbagai titik potong yang berbeda. Tabel 4 menunjukkan hasil uji validitas dengan titik potong skor parameter klinis yang memberi beberapa hasil terbaik.

Tabel 4 menunjukkan skor multivariat $\mathrm{C}$ dan $\mathrm{D}$ mempunyai imbangan nilai sensitivitas dan spesifisitas yang lebih baik dibanding dengan skor yang lain. Akan tetapi, jika akan digunakan sehari-hari, skor multivariat C lebih praktis karena terdiri atas 4 parameter klinis perdarahan pada sejumlah besar subyek adalah gangguan pembekuan darah yang mungkin berhubungan dengan defisiensi vitamin $\mathrm{K}$, yang juga dapat menjelaskan temuan usia yang lebih muda.

Kami menemukan perdarahan subdural merupakan yang terbanyak, sedangkan penelitian sebelumnya melaporkan bahwa perdarahan intraserebral lebih banyak terjadi pada anak. ${ }^{5-7,10}$ Perbedaan tersebut mungkin dikarenakan usia subyek pada penelitian ini lebih muda. Pada anak yang lebih muda, kecenderungan perdarahan subdural terjadi akibat tulang tengkorak yang masih elastis sehingga adanya akselerasi dan deselerasi pada regio oksipital dan fisura interhemisfer posterior menyebabkan perdarahan karena di regio tersebut sutura lambdoidea dan sutura sagitalis bertumpang tindih, akibatnya pergerakan tulang dapat menyebabkan robekan dari sinus duramater. ${ }^{6,11}$

Kami menemukan kadar $\mathrm{Hb}<7 \mathrm{~g} / \mathrm{dL}$, pemanjangan apTT, GCS $<8$ dan penurunan refleks cahaya merupakan parameter yang dapat memprediksi mortalitas. Penelitian sebelumnya melaporkan bahwa

Tabel 4. Hasil uji validitas dari titik potong skor parameter klinis

\begin{tabular}{cccccccccc}
\hline Analisis multivariat & COP & total skor & SEN & SPEC & PPV & NPV & RKP & RKN & Akurasi \\
\hline A & 2 & 4 & 93,94 & 42,72 & 34,44 & 95,62 & 1,64 & 0,14 & 55,15 \\
B & 4 & 7 & 81,8 & 66,02 & 43,55 & 91,89 & 1,25 & 1,22 & 69,85 \\
C & 6 & 10 & 72,7 & 77,67 & 51 & 89,89 & 3,25 & 0,35 & 76,47 \\
D & 10 & 14 & 72,7 & 77,67 & 51 & 89,89 & 3,25 & 0,35 & 76,47 \\
\hline
\end{tabular}

SEN=sensitivitas; $\mathrm{SPEC}=$ spesifisitas; $\mathrm{PPV}=$ positive predictive value; $\mathrm{NPV}=$ negative predictive value;

$\mathrm{RKP}=$ rasio kemungkinan positif; $\mathrm{RKN}=$ rasio kemungkinan negatif; $\mathrm{COP}=$ cut off point

dengan cut off point lebih dari 6 dan skor maksimal 10. Skor multivariat $\mathrm{C}$ mungkin dapat diajukan untuk digunakan sebagai alat untuk memprediksi mortalitas perdarahan intrakranial spontan pada anak usia kurang dari 1 tahun. Beberapa sistem skoring lain dengan variasi bobot parameter yang berbeda juga coba disusun, tetapi memberikan hasil serupa dengan sistem skoring A-D.

\section{Pembahasan}

Rasio jumlah antara anak yang berusia 1-3 bulan dengan anak yang berusia > 3-12 bulan adalah 12,6:1. Sejumlah besar subyek mengalami pemanjangan $\mathrm{p} T$ dan apTT, serta memiliki riwayat tidak mendapatkan suntikan vitamin $\mathrm{K}$, maka nampaknya penyebab adanya gangguan perdarahan akan sangat memengaruhi mortalitas, dengan angka kematian subyek dengan gangguan perdarahan hingga $41 \% .{ }^{10,12,13}$ Pemanjangan apTT menunjukkan derajat gangguan perdarahan dan kadar $\mathrm{Hb}$ dapat berhubungan dengan derajat dan lama perdarahan yang terjadi. Penurunan GCS dan refleks cahaya mungkin mencerminkan derajat proses desak ruang akibat peningkatan tekanan intrakranial.

Jumlah fokus dan lokasi perdarahan tidak memengaruhi prognosis. Temuan ini berbeda dengan data terdahulu yang menunjukkan bahwa perdarahan lebih dari satu lokasi dan jenis perdarahan subdural memiliki prognosis lebih buruk. ${ }^{13,14}$ Perbedaan tersebut kemungkinan dikarenakan penyebab perdarahan dan lebih banyaknya perdarahan subdural pada penelitian kami. Kami tidak memperhitungkan pengaruh jumlah perdarahan, jenis operasi, dan lama rawat yang 
merupakan keterbatasan penelitian ini karena faktor tersebut mungkin dapat berpengaruh. ${ }^{15-17}$

Penelitian kami mencoba membuat suatu sistem skoring yang dapat meramalkan mortalitas pada anak usia kurang dari satu tahun dengan perdarahan intrakranial spontan. Sistem skoring dibuat berdasarkan parameter klinis yang ditemukan dengan alokasi bobot parameter yang berbeda. Hasil akhir menunjukkan tidak didapatkan suatu sistem skoring yang memiliki keseimbangan sensitivitas, spesifisitas, dan akurasi yang ideal. Meskipun demikian, sistem skoring yang didapat masih bermanfaat dan dapat digunakan untuk skrining pada pasien yang mungkin memiliki prognosis lebih buruk. Dibutuhkan penelitian lanjutan dengan subyek yang lebih homogen (usia yang dipersempit dan etiologi yang lebih spesifik) dengan mengikutkan parameter klinis lain, seperti jumlah perdarahan, tindakan medis yang telah diberikan, titik mulai pengamatan yang seragam serta metode penelitian prospektif.

\section{Daftar pustaka}

1. Alfan H, Rita MD, Ansori SD. Clinical predictor of intracranial hemorrhage in children. Paeditr Indones 2012;52 Suppl 1:S15-24.

2. Billmire ME, Myers PA. Serious head injury in infants:accident or abuse. Pediatrics1985;75:340-2.

3. Blom I, DeSchryver EL, Kappelle LJ. Prognosis of haemorrhagic stroke in childhood: a long-term follow-up study. Dev Med Child Neurol 2003;45:233-9.

4. Grenees DS, Schutzman SA. Clinical indicators of intracranial injury in head-injured infants. Pediatrics 1999;104:861-7.

5. Meyer-Heim AD, Boltshauser E. Spontaneous intracranial haemorrhage in children: aetiology, presentation and outcome. Brain Dev 2003;25:416-21.

6. Duhaime AC, Sutton LN. Head injury in the pediatric patient. Dalam: Tindall GT, Cooper PR, Barrow DL, penyunting. The practice of neurosurgery.Edisi ke-2. Baltimore: William \& Wilkins; 1996.h.1564-2340.

7. Gupta SN, Kechli AM, Kanam US. Intracranial hemorrhage in term newborns. Pediatr Neurosurg 2009;40:115-9.

8. Hubbard D, Tobias JD. Intracerebral hemorrhage due to hemorrhagic disease of the newborn and failure to administer vitamin $\mathrm{K}$ at birth. South Med J 2006;99:1216-20.

9. Jhawar BS, Ranger A, Steven DA, Del Maestro RF. A follow-up study of infants with intracranial hemorrhage at full-term. Can J Neurol Sci 2005;32:332-9.

10. Kardana M, Kari K, Widia M. Prognostic factors of intracranial hemorrhage. Paeditr Indones 2003;43:1419.

11. Morris MW, Smith S, Cressman J, Ancheta J. Evaluation on infants with subdural hematoma who lack external evidence of abuse. Pediatrics 2000;105:549-53.

12. Krugman RD, Bays JA, Chadwick DL. Shaken baby syndrome: inflicted cerebral trauma. Pediatrics 1993;92:872-5.

13. Kumar R, Shukla D, Mahapatra AK. Spontaneous intracranial hemorrhage in children. Pediatr Neurosurg 2009;45:37-45.

14. de Ribaupierre S, Rilliet B, Cotting J, et al. A 10year experience in paediatric spontaneous cerebral hemorrhage: which children with headache need more than a clinical examination. Swiss Med Wkly 2008;138:59-69.

15. Lerner JT, Giza CC. Traumatic brain injury in children. Dalam: Galvani DW, Cawley JR, penyunting. Pediatric neurology: Principles and practice. St. Louis: Mosby Company; 2012.h.1098-101.

16. Letourne MA, Jaffe DM. Craniocerebral trauma. Dalam: Reisdorf EJ, Roberts MR, Wiegestein JG, penyunting. Pediatric emergency medicine. Philadelphia: WB Saunders Company; 2002.h.844-55.

17. Lo WD, Lee J, Rusin J.Intracranial hemorrhage in children: an evolving spectrum. Arch Neurol 2008;65:1629-33. 